Abstract-The Atlantic mackerel (Scomber scombrus) has a wide distribution off North America that changes substantially seasonally and interannually, challenging attempts to track changes in stock size. We used egg collections to develop an index of spawning stock biomass for the southern contingent of Atlantic mackerel that spawns in U.S. waters. These results were combined with those from an egg survey of the northern contingent that spawns in the Gulf of St. Lawrence, Canada, to develop the only available stockwide index. Egg production of Atlantic mackerel in the western North Atlantic Ocean has dropped $>90 \%$ from the 1980 s to the $2010 \mathrm{~s}$. The contribution of the southern contingent has generally been around 5-10\%, except for during the late 1970 s and early 1980 s when it was $30-40 \%$. On the continental shelf of the northeastern United States, there has been a northeastward shift in the distribution of eggs of Atlantic mackerel, with low levels of egg production recently at the historically important spawning location off southern New England. Overall, the index of spawning stock biomass generated from surveys in the waters of the United States and Canada provides a much needed means of tracking fluctuations in the biomass of this commercially valuable migratory species.

Manuscript submitted 12 September 2019. Manuscript accepted 23 April 2020. Fish. Bull. 118:120-134 (2020). Online publication date: 4 May 2020. doi: 10.7755/FB.118.2.2

The views and opinions expressed or implied in this article are those of the author (or authors) and do not necessarily reflect the position of the National Marine Fisheries Service, NOAA.

\section{Changes in the spawning distribution and biomass of Atlantic mackerel (Scomber scombrus) in the western Atlantic Ocean over 4 decades}

\author{
David E. Richardson (contact author) ${ }^{1}$ \\ Lauren Carter ${ }^{2}$ \\ Kiersten L. Curti ${ }^{3}$ \\ Katrin E. Marancik ${ }^{2}$ \\ Martin Castonguay ${ }^{4}$ \\ Email address for contact author: david.richardson@noaa.gov \\ ${ }^{1}$ Northeast Fisheries Science Center \\ National Marine Fisheries Service, NOAA \\ 28 Tarzwell Drive \\ Narragansett, Rhode Island 02882 \\ ${ }^{2}$ Integrated Statistics \\ 28 Tarzwell Drive \\ Narragansett, Rhode Island 02882 \\ ${ }^{3}$ Northeast Fisheries Science Center \\ National Marine Fisheries Service, NOAA \\ 166 Water Street \\ Woods Hole, Massachusetts 02543 \\ ${ }^{4}$ Maurice Lamontagne Institute \\ Fisheries and Oceans Canada \\ 850 de la Mer Road \\ Mont-Joli, Quebec G5H 3Z4, Canada
}

The Atlantic mackerel (Scomber scombrus) is a migratory, small pelagic species that supports important fisheries throughout the North Atlantic Ocean. In recent decades, the majority of worldwide landings of Atlantic mackerel has occurred in the eastern Atlantic Ocean, where the challenges of assessing and managing this ecologically important species are well documented. Specifically, for Atlantic mackerel in the eastern Atlantic Ocean, a substantial increase in abundance and a shift and expansion in distribution started around 2005. This distribution change led to increased difficulty in surveying the population (Nøttestad et al., 2016), the development of new regional fisheries (Astthorsson et al., 2012), conflicts among nations in quota allocations (Spijkers and Boonstra, 2017), and potentially regional changes in the abundance of mackerel predators and prey (MacKenzie et al., 2014; Óskarsson et al., 2016). The results of a number of analyses indicate that the warming of waters in the North
Atlantic Ocean is the cause of these changes (Hughes et al., 2014; Berge et al., 2015; Jansen et al., 2016). More recently, the assessment has indicated a decline in biomass of Atlantic mackerel in the eastern Atlantic Ocean and the need for quota reductions, presenting new assessment and management challenges.

Atlantic mackerel in the western North Atlantic Ocean have also shifted distribution, although the extent and causes of this shift are less certain than for Atlantic mackerel in the eastern Atlantic Ocean, as are the effects on resource surveys, stock assessments, and the availability of Atlantic mackerel to regional fisheries. Atlantic mackerel in the western Atlantic Ocean are considered a single population (Sette, 1950), with a southern contingent that spawns in U.S. waters offshore of southern New England and in the western Gulf of Maine (Berrien, 1978) and a northern contingent that spawns in waters of Canada, primarily in the southern 
Gulf of St. Lawrence (Sette, 1943; Grégoire ${ }^{1}$ ). Results from tagging and cohort tracking work, primarily done in the 1930s (Sette, 1950), indicate that these 2 contingents mix on the continental shelf of the northeastern United States from the late fall through the spring but then separate during the late-spring spawning season and through much of the summer.

As with Atlantic mackerel in the eastern Atlantic Ocean, relative catches in different regional fisheries in the western Atlantic Ocean have changed over time, in part because of distribution shifts within the population. Additionally, across the entire western North Atlantic Ocean, there have been substantial multi-decadal cycles in landings, with a notable recent $88 \%$ decline between 2006 and 2015 to the lowest levels since the early 1800 s (Hoy and Clark ${ }^{2}$; NEFSC, 2018). During this decline, only small portions of the quotas of both Canada and the United States were usually harvested despite industry capacity and market demand, leading to questions about why the industry was underperforming relative to expectations.

Two alternative hypotheses have been proposed to explain the decline in catch of Atlantic mackerel in the western Atlantic Ocean over the past 10-15 years. The first hypothesis is that warming waters in the western Atlantic Ocean (Shearman and Lentz, 2010) resulted in a shift in mackerel distribution that reduced availability to the fishery (Overholtz et al., 2011). This hypothesis of a change in distribution was supported by the results from a bottom-trawl survey conducted off the northeastern United States, results that included a northeastward shift in survey catch and mean abundance per tow near the highs of the time series (Overholtz et al., 2011). Similarly, a northeastward shift in landings of Atlantic mackerel in waters of Canada from Nova Scotia and the Gulf of St. Lawrence to Newfoundland (Grégoire et al. ${ }^{3}$ ) indicated that the distribution of Atlantic mackerel was changing. A stock assessment that estimated high biomass and very low exploitation rates of Atlantic mackerel in 2006 was consistent with the hypothesis that the population of Atlantic mackerel was robust but availability to the fishing industry had declined (NEFSC, 2006).

The alternate hypothesis is that a population decline, rather than a distribution shift, was responsible for the landings decline. This alternate hypothesis was supported by the decline in the index of egg abundance for Atlantic mackerel in the Gulf of St. Lawrence (northern contingent) (Grégoire et al. ${ }^{4}$ ), truncated age-structure in fishery

\footnotetext{
${ }^{1}$ Grégoire, F. (ed.). 2000. The Atlantic mackerel (Scomber scombrus L.) of NAFO subareas 2 to 6-Part 1. Can. Stock Assess. Secr. Res. Doc. 2000/021, 172 p. [Available from website.]

${ }^{2}$ Hoy, D. L., and G. M. Clark. 1967. Atlantic mackerel fishery, 1804-1965. U.S. Fish. Wildl. Serv., Bur. Commer. Fish., Fish. Leafl. 603, 9 p. [Available from website.]

${ }^{3}$ Grégoire, F., C. Lévesque, J.-L. Beaulieu, and M.-H. Gendron. 2008. Results of the Atlantic mackerel (Scomber sombrus L.) egg survey conducted in the southern Gulf of St. Lawrence in 2007. Can. Sci. Advis. Secr. Res. Doc. 2008/081, 50 p. [Available from website.]

${ }^{4}$ Grégoire, F., M.-F. Gendron, J.-L. Beaulieu, and I. Levesque. 2013. Results of the Atlantic mackerel (Scomber scombrus L.)
}

catches despite low landings in both the United States and Canada, truncated age-structure in the U.S. bottomtrawl survey, and results of a stock assessment in 2016 in Canada indicating that the biomass of the northern contingent had reached a historic minimum in 2012 (DFO, 2017). A joint U.S.-Canada stock assessment conducted in 2010 was consistent with this view of the stock (Deroba et al., 2010), but that assessment was not incorporated into management decisions by either nation because of severe retrospective patterns in the assessment model and unresolved conflicts in the data, in particular between fishery catches and the index of abundance from the U.S. bottom-trawl survey.

One of the long-running challenges in assessing the stock of Atlantic mackerel in the western Atlantic Ocean is that the fishery-independent indices that are generally used for this stock, an egg survey in Canada (1982present) and a bottom-trawl survey in the United States (1968-present), do not cover the entire range of this stock. Therefore, the trends in each index may be affected by changes in both abundance and availability associated with distribution shifts.

The egg survey in Canada uses the daily egg production method (Grégoire et al. ${ }^{4}$ ), a well-established approach that is used throughout the world (Bernal et al., 2012), including in the multi-nation triennial survey of Atlantic mackerel in the eastern Atlantic Ocean (Dransfeld et al., 2005). For the index of spawning biomass in Canada, a systematic plankton survey is used to develop daily egg production estimates, and gonadosomadic index measurements from landings are used to evaluate seasonality of spawning to scale daily egg production to annual egg production. Fecundity estimates are then used to calculate spawning stock biomass.

Within U.S. waters, there have been sporadic efforts, each with a slightly different analytical approach, to develop estimates of annual egg production or spawning stock size of Atlantic mackerel. These estimates include 64 trillion eggs and 320 million individuals in 1932 (Sette, 1943), 18 million individuals in 1966 (Berrien and Anderson ${ }^{5}$ ), 303 trillion eggs and 1220 million individuals in 1977 (Berrien et al., 1984), and 56 trillion eggs and 240 million individuals in 1987 (Berrien $^{6}$ ). The 1987 survey was the only analysis to compare egg production in the United States and Canada in the same year, with only $10 \%$ of stock-wide egg production being

egg surveys conducted in the southern Gulf of St. Lawrence from 2008 to 2011. Can. Sci. Advis. Secr. Res. Doc. 2013/035, $57 \mathrm{p}$. [Available from website.]

${ }^{5}$ Berrien, P. L., and E. D. Anderson. 1976. Scomber scombrus spawning stock biomass estimates in ICNAF subarea 5 and statistical area 6, based on egg catches during 1966, 1975 and 1976. Int. Comm. Northwest Atl. Fish., ICNAF Res. Doc. 76/XII/140, 10 p. [Available from website.]

${ }^{6}$ Berrien, P. L. 1988. Atlantic mackerel, Scomber scombrus, total annual egg production and spawner biomass estimates for the Gulf of St. Lawrence and northeastern United States waters, 1987. Northeast Fish. Sci. Cent., Sandy Hook Lab. Rep. 88-02, 18 p. [Available from Northeast Fish. Sci. Cent., 166 Water St.,Woods Hole, MA 02543-1026.] 
estimated to occur in U.S. waters. After 1987, there was no further work on egg production of Atlantic mackerel in U.S. waters.

Our study focused on analyzing archived egg samples from a multipurpose plankton survey on the northeastern U.S. continental shelf, with the goal of creating a time series of egg production for the southern contingent of Atlantic mackerel. The specific objectives of this study were 1) to create a joint U.S.-Canada stock-wide index of spawning biomass for Atlantic mackerel that could be evaluated in stock assessments, 2) to estimate the proportion of spawning by each contingent, 3) to document shifts in the distribution of spawning by the southern contingent, and 4) to reanalyze historic egg data for Atlantic mackerel by using the same technique. The reanalysis of data from the 1930s and 1960s was undertaken to put the recent results into a broader historical context, because of questions about how the productivity of the stock has changed over longer time scales. This study was done in preparation for the stock assessment conducted by the Northeast Fisheries Science Center (NEFSC) in 2017 for Atlantic mackerel in the western North Atlantic Ocean (NEFSC, 2018); this stock assessment was supported in part by Fisheries and Oceans Canada.

\section{Materials and methods}

\section{Field collections}

Eggs from the southern contingent of Atlantic mackerel were sampled during the Marine Resources, Monitoring, Assessment, and Prediction (MARMAP) program, a longterm, fishery-independent monitoring survey, from 1977 to 1987 and during the NEFSC Ecosystem Monitoring (EcoMon) program from 1999 to the present (Richardson et al., 2010; Walsh et al., 2015). The MARMAP program sampled both fixed stations and random stratified stations, whereas the EcoMon program uses solely a random stratified design (Fig. 1). Both programs involved dedicated surveys, as well as operations integrated into interdisciplinary fall and spring bottom-trawl surveys.

At least 1 of the $6-8$ shelf-wide yearly MARMAP cruises typically occurred during late April-June, the peak period of spawning of Atlantic mackerel, with 2 cruises occurring during the spawning season in 1987. As part of the EcoMon program, 1 of 6 seasonal surveys conducted in May or June coincides with spawning of Atlantic mackerel. The surveys completed before (bottom-trawl survey in March-April) and after (dedicated survey in August) the May or June survey rarely capture Atlantic mackerel in early life stages. Complete spatial coverage in the United States of the Atlantic mackerel spawning area, which includes the waters off the mid-Atlantic states, southern New England, and the western Gulf of Maine (Fig. 1), was achieved during surveys of the EcoMon program conducted in May or June in all years except 2003, 2008, 2012, and 2014 .

All plankton tows of these surveys used a $61-\mathrm{cm}$ bongo frame that was fished from the sea surface to within

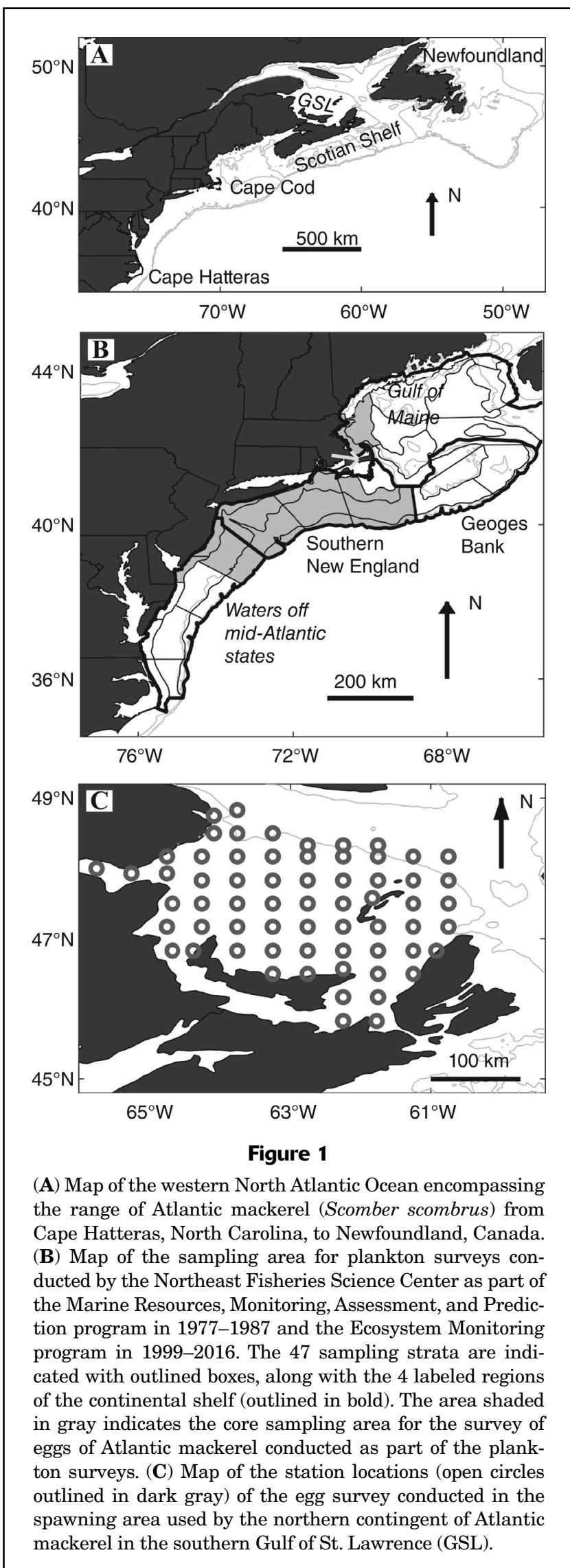


$5 \mathrm{~m}$ of the seafloor or to a maximum depth of $200 \mathrm{~m}$. Ichthyoplankton sampling used a 505- $\mu \mathrm{m}$ mesh net during MARMAP program surveys and a 333- $\mu$ m mesh net during EcoMon program surveys. Eggs of Atlantic mackerel are $>1 \mathrm{~mm}$ in diameter and are not extruded through either mesh size. All samples were fixed at sea in $3 \%$ formalin buffered with seawater.

The hydrography of the water column during the MARMAP and EcoMon program surveys was typically measured with an SBE $19^{7}$, SBE 19plus, or SBE 19plus V2 SeaCAT conductivity, temperature, and depth (CTD) unit (Sea-Bird Scientific, Bellevue, WA) mounted directly above the bongo frame. A few exceptions to this method did occur. During MARMAP program cruises conducted in 1977 (NO7702 and DE7705), 1982 (AL8206), and 1987 (WI8701), low-vertical-resolution expendable bathythermographs (XBTs) were used. During cruise WI8701, water column temperatures were measured at every other station with an XBT and sea-surface temperatures were measured only at alternating stations. Additionally, at $<1 \%$ of all stations, exclusive of 1987, temperatures for the full water column were not successfully measured, although sea-surface temperatures were recorded. All CTD data have been uploaded to the National Oceanographic Data Center (World Ocean Database, available from website) and can be accessed at the NEFSC ftp site.

\section{Laboratory processing}

Initial processing of most plankton samples, including the removal and enumeration of fish eggs, occurred at the Plankton Sorting and Identification Center in Szczecin, Poland. Eggs of Atlantic mackerel were then identified and developmentally staged at the NEFSC. All eggs collected during MARMAP program surveys were identified to the lowest possible taxonomic level (Berrien and Sibunka ${ }^{8}$ ). For the samples from EcoMon program surveys, only eggs of Atlantic mackerel were identified and staged.

Atlantic mackerel eggs can be distinguished from those of all other species at all stages of development, although there is some overlap in characters with eggs of cusk (Brosme brosme). The cusk is a rare species on the continental shelf of the northeastern United States, with eggs that have a textured rather than smooth outer chorion (Berrien, 1975). Egg staging for samples collected during EcoMon program surveys matched the criteria used in the egg survey in Canada: stage 1-fertilization to blastopore closure; stage 2-first appearance of the embryo to the embryo reaching half the circumference of the egg; stage 3-embryo extends from half to the full circumference of the egg; stage 4-embryo exceeds the full circumference of the egg to hatching; and stage 5-eggs unfertilized or

\footnotetext{
${ }^{7}$ Mention of trade names or commercial companies is for identification purposes only and does not imply endorsement by the National Marine Fisheries Service, NOAA.

${ }^{8}$ Berrien, P. L., and J. D. Sibunka. 2006. A laboratory guide to the identification of marine fish eggs collected on the northeast coast of the United States, 1977-1994. Northeast Fish. Sci. Cent. Ref. Doc. 06-21, 162 p. [Available from website.]
}

dead eggs with an opaque look (Girard ${ }^{9}$ ). The criteria used to delineate stage-1 eggs were consistent across all sampling, but the definition of later egg stages differed between MARMAP program surveys and both the egg survey in Canada and the EcoMon program surveys. We restaged the later-stage eggs collected during MARMAP program surveys to match the criteria used in the survey in Canada. A subset of egg identifications and stages of the southern contingent of Atlantic mackerel were verified during an inperson collaboration with L. Girard at the Maurice Lamontagne Institute, Mont-Joli, Quebec; L. Girard performs all egg identifications for the egg survey conducted in Canada.

\section{Calculation of egg production}

Daily egg production (DEP) per unit area at each station was calculated by using the following equation:

$$
D E P=\text { Abundance }(\text { Stage } 1 \text { and } 5) \times \frac{24}{I},
$$

where Abundance $=$ number of eggs identified to be in (Stage 1 and 5) stages 1 and 5 of development; and $I=$ the incubation time of stage 1 eggs in hours for a given temperature and is based on experimental work (Lockwood et al. ${ }^{10}$ ):

$$
I=\mathrm{e}^{(-1.61 \ln (\mathrm{T})+7.76)},
$$

where $T=$ the average temperature (in degrees Celsius) of the first $10 \mathrm{~m}$ of the water column.

For our analysis, this definition of $T$ is consistent with data from the survey in Canada and with the vertical distribution of eggs of Atlantic mackerel in U.S. waters (Sette, 1943). Average temperatures at depths of 0-10 m were based on the concurrent CTD or XBT data, with seasurface temperature used for the limited number of stations without measurements from the water column. We calculated the stratified mean daily egg production per square meter across the sampling area for each survey, and we scaled this mean to total daily egg production by using the total area of the sampled strata. Coefficients of variation for the stratified mean daily egg production were calculated by using the standard approach.

Spawning seasonality is used to estimate annual egg production from a measure of daily egg production. In the Gulf of St. Lawrence, seasonality of spawning is based on a logistic function fit to the average gonadosomadic index by day of year for individuals caught in the fishery (Grégoire et $\mathrm{al}^{4}{ }^{4}$ ). In contrast, the United

\footnotetext{
${ }^{9}$ Girard, L. 2000. Identification of mackerel (Scomber scombrus L.) eggs sampled during abundance surveys in the southern Gulf of St. Lawrence. In The Atlantic mackerel (Scomber scombrus L.) of NAFO subareas 2 to 6 (F. Grégoire, ed.), p. 119-137. Can. Stock Assess. Secret. Res. Doc. 2000/021. [Available from website.]

${ }^{10}$ Lockwood, S. J., J. H. Nichols, and S. H. Coombs. 1977. The development rates of mackerel (Scomber scombrus L.) eggs over a range of temperatures. ICES CM 1977/J:13, 13 p. [Available from website.]
} 
States fishery neither targets nor catches many Atlantic mackerel during the spawning season $(<2 \%$ of landings in 2000-2015 occurred in May and June). Instead, we derived an average spawning seasonality function for the U.S. spawning ground from a larval index method (Richardson et al., 2010) that uses multi-decadal data on abundance at age of larval Atlantic mackerel to fit a larval mortality function, an annual index of larval abundance, and a 3-parameter skewed logistic function representing spawning seasonality:

$$
P_{\mathrm{D}}=\left(\frac{\mathrm{e}^{\mathrm{a}+\mathrm{bD}}}{1+\mathrm{e}^{\mathrm{a}+\mathrm{bD}}}\right)^{1 / \mathrm{c}},
$$

where $a(-7.3110)=$ an estimated model parameter;

$b(0.0694)=$ an estimated model parameter;

$c(0.0828)=$ an estimated model parameter; and

$P_{\mathrm{D}}=$ the cumulative proportion of spawning at a day of year $D$.

The resulting spawning season represents the average for the time series rather than a year-specific estimate.

For the egg surveys in Canada and the United States, total annual egg production (AEP) is calculated by dividing the daily egg production (DEP) by the proportion of eggs estimated to be spawned on the mean day $(D)$ stations were sampled on the survey:

$$
A E P=D E P /\left(P_{(\mathrm{D}+0.5)}-P_{(\mathrm{D}-0.5)}\right) .
$$

Annual egg production on the continental shelf off the northeastern United States was also calculated for cruises undertaken in 1932 and 1966. These surveys provide an estimate of regional egg production prior to the substantial landings of the early 1970s. The sampling methods and laboratory work for these surveys differed from those undertaken during cruises of the MARMAP and EcoMon programs, and in some cases modifications to methods were required (Suppl. Material).

\section{Calculation of spawning stock biomass}

Spawning stock biomass (SSB) is calculated on the basis of total annual egg production (AEP) from the plankton surveys and annual fecundity from a reproductive study:

$$
S S B=\frac{(A E P \times W)}{F \times R \times 10^{6}},
$$

where $W=$ mean weight (in grams) of spawning fish;

$F=$ mean female fecundity;

$R=$ proportion female; and

$10^{6}=$ the value that converts grams to metric tons.

In the Gulf of St. Lawrence, annual fecundity is estimated on the basis of the measured weight of mature ovaries, which has been found to be a better predictor than length or body weight (Pelletier, 1986). Fecundity sampling of the southern contingent occurred in 1977 and 1987, with estimates of fecundity at length similar to values from surveys in Canada for Atlantic mackerel $<35 \mathrm{~cm}$ in fork length (FL) but higher than those values for fish at larger sizes (Morse, 1980; Griswold and Silverman, 1992). In both U.S. studies, an allometric fecundity-weight relationship was also estimated. With an allometric fecundity-weight relationship, information on the size structure of spawners of just the southern contingent is required to calculate spawning stock biomass from a measure of total egg production; this information is unavailable. In calculating spawning stock biomass for the southern contingent, we used the annual fecundity estimates for the northern contingent of Atlantic mackerel.

\section{Sensitivity analyses}

The calculation of annual egg production for the southern contingent of Atlantic mackerel relies on parameters and functions that were derived from studies performed in other regions or different years. To the extent possible, we maintained consistency with the analysis used in the survey of the Gulf of St. Lawrence in order to create a single internally consistent stock-wide index. We used sensitivity analyses to evaluate the influence of different components of the calculations on both the trend and scale of the index.

Stage-specific egg incubation times are derived from laboratory experiments with a range of temperature treatments. Mendiola et al. (2006) repeated the study we used, Lockwood et al. ${ }^{10}$, but sampled at more frequent time intervals and incubated eggs at lower densities, because of concerns about oxygen depletion. Both studies were done in the Bay of Biscay in the northeastern Atlantic Ocean. The equation for times of stage-1 egg development in Mendiola et al. (2006) was as follows:

$$
I=\mathrm{e}^{(-1.313 \ln (\mathrm{T})+6.902)} .
$$

These egg development times were shorter than those reported in Lockwood et al. ${ }^{10}$ at all but the highest temperatures.

A common finding in studies of vertical distributions of eggs of Atlantic mackerel is that eggs occur mostly above the thermocline (Sette, 1943; Ware and Lambert, 1985; de Lafontaine and Gascon, 1989; Coombs et al., 2001). During sampling on the continental shelf of the northeastern United States, eggs were primarily within the upper $10 \mathrm{~m}$ of the water column (Sette, 1943), matching our use of the average water temperatures at depths from the surface to $10 \mathrm{~m}$. We evaluated 2 alternative temperature measures in the incubation time calculations: sea-surface temperature and average temperature in the upper $20 \mathrm{~m}$ of the water column.

The calculation of daily egg production in the surveys in Canada and Europe does not adjust for mortality of eggs in stage 1 of development (Dransfeld et al., 2005; Grégoire et al. ${ }^{4}$ ). Egg mortality estimates based on field measurements range from 0.098/d to 0.540/d (Berrien et al., 1981; Kendall and Gordon, 1981; Thompson, 1989; Portilla et al., 2007). We used egg mortality estimates of $0.20 / \mathrm{d}$ and $0.55 / \mathrm{d}$ in our sensitivity analyses. Stage-1 egg abundances were scaled up by using a correction factor that corresponded to the number of eggs spawned (i.e., the 
start of stage 1) versus the average number of stage-1 eggs at any point in time from spawning to the transition from stage 1 to stage 2 :

$$
\text { Correction Factor }=\frac{\left(\frac{I}{24}\right)}{\frac{1}{-Z}\left(\mathrm{e}^{-Z\left(\frac{\mathrm{I}}{24}\right)}-1\right)},
$$

where $Z$ = daily mortality rate; and

$I=$ incubation time in hours.

This correction factor is applied on a sample-by-sample basis and varies on the basis of temperature-dependent incubation times.

Our spawning seasonality function was not estimated annually. We recalculated annual egg production with shifts in this annual spawning season of 14 and $7 \mathrm{~d}$ both forward and backward, for a total range of $28 \mathrm{~d}$. For comparison, within the Gulf of St. Lawrence, the median day of spawning estimated through gonad sampling ranged from day 166 to day 179 (15-28 June) for a total range of $13 \mathrm{~d}$ (Grégoire et al. ${ }^{4}$ ).

We evaluated the effect of changes made in each of the 9 sensitivity analyses on the scale and trend of annual egg production. These evaluations included 1 analysis of egg development, 2 analyses of vertical distribution, 2 analyses of egg mortality, and 4 analyses of spawning seasonality. The annual egg production for each year in each sensitivity analysis was divided by the baseline for that year. The average of this metric quantifies the effect of each sensitivity analysis on the scale of annual egg production, and the standard deviation quantifies interannual variability in relative index values once the difference in scale is accounted for. We also plotted a time series of the relative difference in estimated annual egg production to evaluate the potential for a temporal bias in the index.

\section{Distribution of spawning and spawning habitat}

Egg distributions were mapped for 5 time periods spanning from 1977 through 2016. We also evaluated trends in the proportion of egg production that occurred in 4 regions on the continental shelf of the northeastern United States: the waters off the mid-Atlantic states, southern New England, Georges Bank, and the Gulf of Maine.

Quotient analysis was used to evaluate the preferred range of sea-surface temperatures for Atlantic mackerel spawning on the northeastern U.S. continental shelf (van der Lingen et al., 2001), an approach previously used to evaluate distributions of adult Atlantic mackerel during the U.S. spring bottom-trawl survey (Overholtz et al., 2011). The quotient for each $1^{\circ} \mathrm{C}$ temperature bin $\left(Q_{\mathrm{T}}\right)$ is calculated as follows:

$$
Q_{\mathrm{T}}=p M_{\mathrm{T}} / p S_{\mathrm{T}}
$$

where $p M_{\mathrm{T}}=$ the proportion of stations positive for eggs of Atlantic mackerel in each temperature bin; and $p S_{\mathrm{T}}=$ the proportion of all stations in each bin.
Quotient values $>1$ indicate that a greater number of stations in the temperature bin were positive for mackerel eggs than was expected on the basis of sampling effort alone, with the significance of the quotient value obtained by using bootstrapping (Bernal et al., 2007; Overholtz et al., 2011).

We used the results of the quotient analysis and a NOAA $1 / 4^{\circ}$ daily analysis, the Optimum Interpolation Sea-Surface Temperature (OISST) product (available from website), to quantify temporal trends in the area with sea-surface temperatures preferentially used by Atlantic mackerel for spawning. The OISST product interpolates measurements from a variety of different sampling methods to develop a map of daily, spatially resolved sea-surface temperatures (Banzon et al., 2016). We quantified the area with preferred spawning temperatures $\left(Q_{\mathrm{T}}>1\right)$ for each year from 1982 through 2016 in the waters off the mid-Atlantic states, southern New England, and the western Gulf of Maine on 19 May, the average peak day of spawning of Atlantic mackerel. Linear regression was used to evaluate trends in the preferred habitat.

\section{Results}

\section{Egg distribution}

The distribution of eggs of Atlantic mackerel on the continental shelf of the northeastern United States shifted northeastward between 1977 and 2015 (Fig. 2). In the late 1970 s and early 1980 s, the majority of egg production typically occurred in southern New England. By the early 2000s, the majority of egg collections occurred in the Gulf of Maine. Since 2010, there has been very little egg production in southern New England.

Significant quotient values $>1$ for eggs of Atlantic mackerel occurred at sea-surface temperatures between $7^{\circ} \mathrm{C}$ and $12^{\circ} \mathrm{C}$. On average during $1982-2016,65 \%$ of the core spawning area for Atlantic mackerel was in the temperature range of $7-12^{\circ} \mathrm{C}$ on 19 May. Over the period of $1982-$ 2016 , there was a decline in preferred spawning habitat of $0.5 \%$ per year, with the smallest areas occurring in 2012 , 2013 , and 2015. This decline was not significant $(P=0.13)$, and interannual variability was high in the area with preferred sea-surface temperatures (Fig. 3).

\section{Egg production and spawning stock biomass}

Annual egg production on the northeastern U.S. continental shelf declined from a high of 213 trillion eggs in 1980 to a low of 653 billion eggs in 2011, with a minimal recovery occurring in recent years (Fig. 4; Suppl. Table 1). The estimated spawning biomass of Atlantic mackerel on the continental shelf of the northeastern United States declined from a high of 390,000 metric tons ( $t$ ) in the late 1970 s to a low of $746 \mathrm{t}$ in 2013 (Suppl. Table 1). In a reanalysis of historic data, annual egg production of the southern contingent, exclusive of the Gulf of Maine, was estimated at 


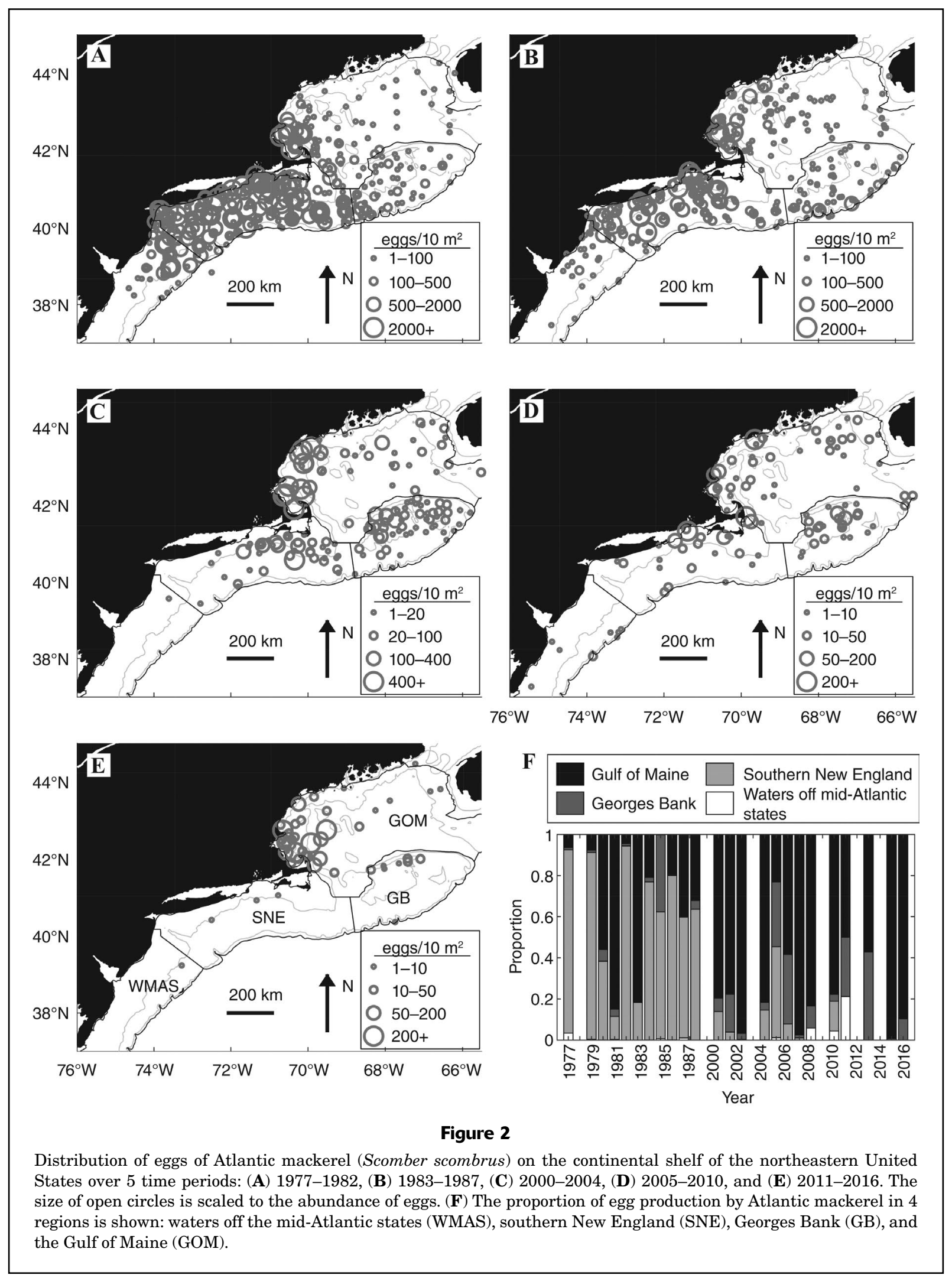




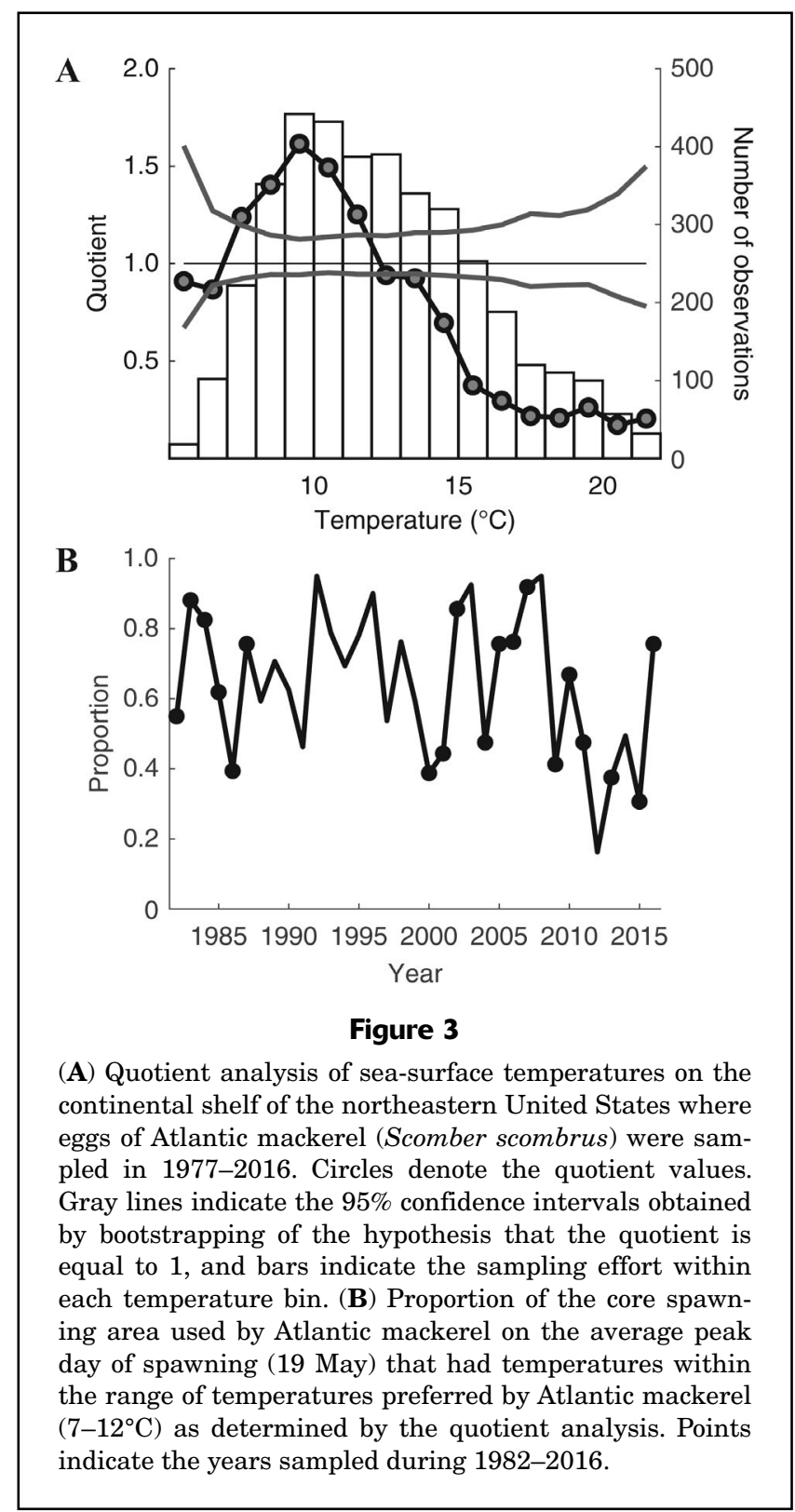

55.1 trillion eggs in 1932 and 12.7 trillion eggs in 1966, within the range of values seen during the past 4 decades (Suppl. Table 2).

Stock-wide estimates of annual egg production from the combined surveys in Canada and the United States declined approximately 55 -fold from a high of 1290 trillion eggs in 1986 to a low of 22.4 trillion eggs in 2013. Despite some interannual differences in fecundity, estimated spawning stock biomass declined by a similar magnitude, from a high of 1.8 million $t$ in 1986 to a low of $29,000 \mathrm{t}$ in 2010. For most of the time series, the southern contingent accounted for $5-15 \%$ of the stock-wide egg production, with the exception of the first years of overlapping time series in 1979 and 1983, when the estimates were 27\% and $43 \%$, respectively (Fig. 4; Suppl. Table 1).

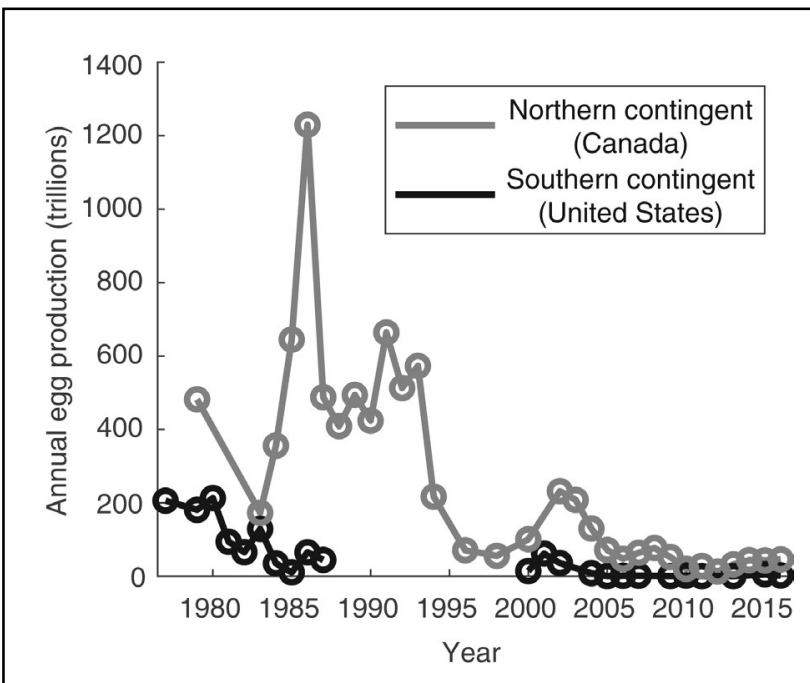

Figure 4

Annual egg production between 1977 and 2016 for 2 contingents of Atlantic mackerel (Scomber scombrus): the northern contingent that spawns in the southern Gulf of St. Lawrence, Canada, and the southern contingent that spawns on the continental shelf of the northeastern United States.

\section{Sensitivity analyses}

Three sensitivity analyses focused on the time of egg development, with each of these changes having a minor effect on the scale and trend of estimates of annual egg production (Figs. 5 and 6). The substitution of an updated relationship of stage-1 egg development and temperature (Mendiola et al., 2006) increased the scale of egg production by $6 \%$ (standard deviation [SD] 5.4). Using seasurface temperature rather than the average temperature of the upper $10 \mathrm{~m}$ of the water column reduced the estimated scale of egg production by $11 \%$ (SD 6.3), and using the temperature of the upper $20 \mathrm{~m}$ of the water column increased the estimated scale of egg production by $16 \%$ (SD 4.5). The results of these 3 analyses did not have obvious temporal patterns (Fig. 6).

Incorporating egg mortality $(Z)$ into the calculations increased average annual egg production estimates by $24 \%$ (SD 5.0) with $Z$ at $0.2 /$ d and by $72 \%$ (SD 16.6) with $Z$ at $0.55 / \mathrm{d}$. The year-to-year variability in these estimates was relatively minor and can be attributed to differences in average incubation times among years leading to different cumulative mortalities of stage- 1 eggs.

Changing spawning seasonality had a notable effect on the estimates of egg production. The use of a spawning seasonality function that shifted the peak day to $14 \mathrm{~d}$ earlier, from 5 May to 19 May, increased the average estimated annual egg production by 93\% (SD 34.3), with notable year-to-year variability (Figs. 5 and 6). For all cruises since 2000 , an increase in annual egg production was observed with this analysis because of the general timing of the survey near to or just after the average peak 
A

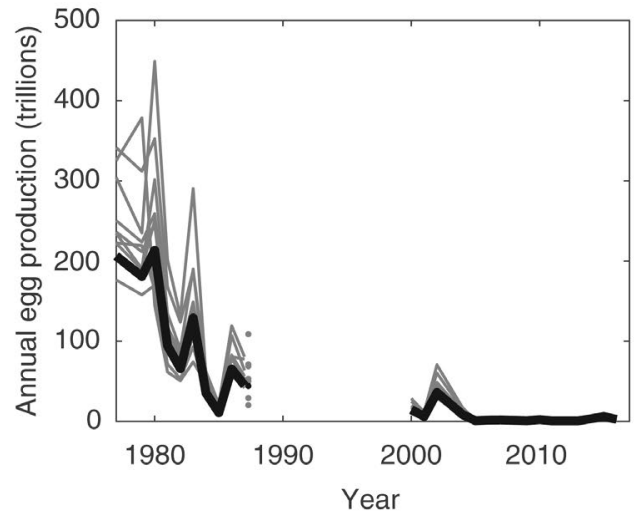

B

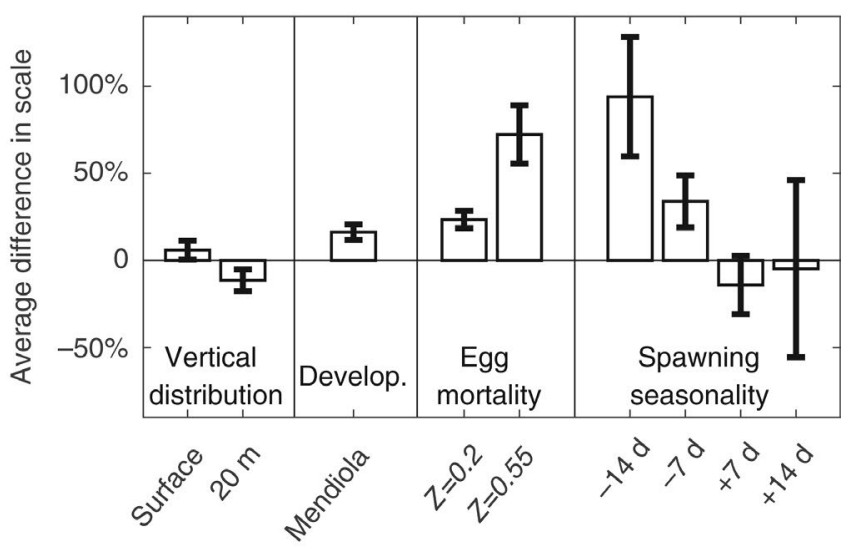

Figure 5

Results of sensitivity analyses conducted to evaluate the influence of 9 components on the trend and scale of a stockwide egg production index for Atlantic mackerel (Scomber scombrus) on the continental shelf of the northeastern United States during 1977-1987 and 1999-2016. (A) Plot of the base index (black line) compared to indices resulting from all 9 sensitivity analyses (gray lines). (B) Average change in the scale of egg production for each of 4 sensitivity analyses that used one of these components: vertical distribution, egg development, egg mortality $(Z)$, and spawning seasonality. Analysis of egg development used an equation from Mendiola et al. (2006) for calculations of the time of stage-1 egg development. Analysis of spawning seasonality shifted the season 7 or $14 \mathrm{~d}$ earlier or later. Error bars indicate standard deviations.

spawning period. A shift of the peak day to $7 \mathrm{~d}$ earlier increased the average scale by $35 \%$ (SD 14.9). Shifts of $7 \mathrm{~d}$ and $14 \mathrm{~d}$ later decreased the average scale by $14.0 \%$ (SD 16.7 ) and $4.7 \%$ (SD 50.8), respectively.

\section{Discussion}

Ichthyoplankton surveys have a long history of use in developing fishery-independent indices of abundance, particularly for migratory pelagic species that may otherwise be difficult to sample in a consistent manner across space and time (Lasker, 1985; Stratoudakis et al., 2006). The egg index we developed for Atlantic mackerel points to a severe decline in the southern contingent of the population in the western Atlantic Ocean over the past few decades, with a comparable decline when the egg indices based on collections in the United States and Canada are combined to evaluate the stock as a whole. The combined U.S.-Canada index potentially provides a more complete depiction of the stock of Atlantic mackerel in the western Atlantic Ocean because it is not as susceptible to changes in availability and seasonal migration patterns. The negative picture of stock trends is consistent with the substantial age-truncation in recent years despite historically low landings. Further evidence of a depleted population comes from observations by members of the commercial fishing industry and data that indicate that commercial landings are well below quotas and from a major decline in catch by the U.S. recreational fishery (which does not have size or bag limits) (NEFSC, 2018).

\section{Potential error and bias in the egg index}

A critical factor in evaluating any fishery-independent index is a thorough assessment of the magnitude of error in the index and the potential sources of bias in both the sampling and analytical techniques that produce the index. As with many other ichthyoplankton-based indices for schooling pelagic species, the egg index for the southern contingent of Atlantic mackerel was only moderately precise (average coefficient of variation: 0.4), as earlystage eggs tend to be patchy in their distribution. However, given the large magnitude of change in the index, concerns about potential sources of bias outweigh concerns about precision. The major change in field sampling protocol during the time series, a decrease in net mesh size from $505 \mu \mathrm{m}$ to $333 \mu \mathrm{m}$, should not affect mackerel egg abundance measurements given their diameter $(>1 \mathrm{~mm})$ and the use of direct flow measurements. A change in personnel identifying eggs also occurred from early to late in the time series. This potential issue was addressed by training new personnel on previously identified eggs and through direct collaboration with Canadian scientists. Although not a direct comparison, low abundances of eggs of Atlantic mackerel in recent years were also evident in a study that genetically identified eggs preserved in ethanol (Lewis et al., 2016). Potential sources of bias in the analytical techniques were considered more 


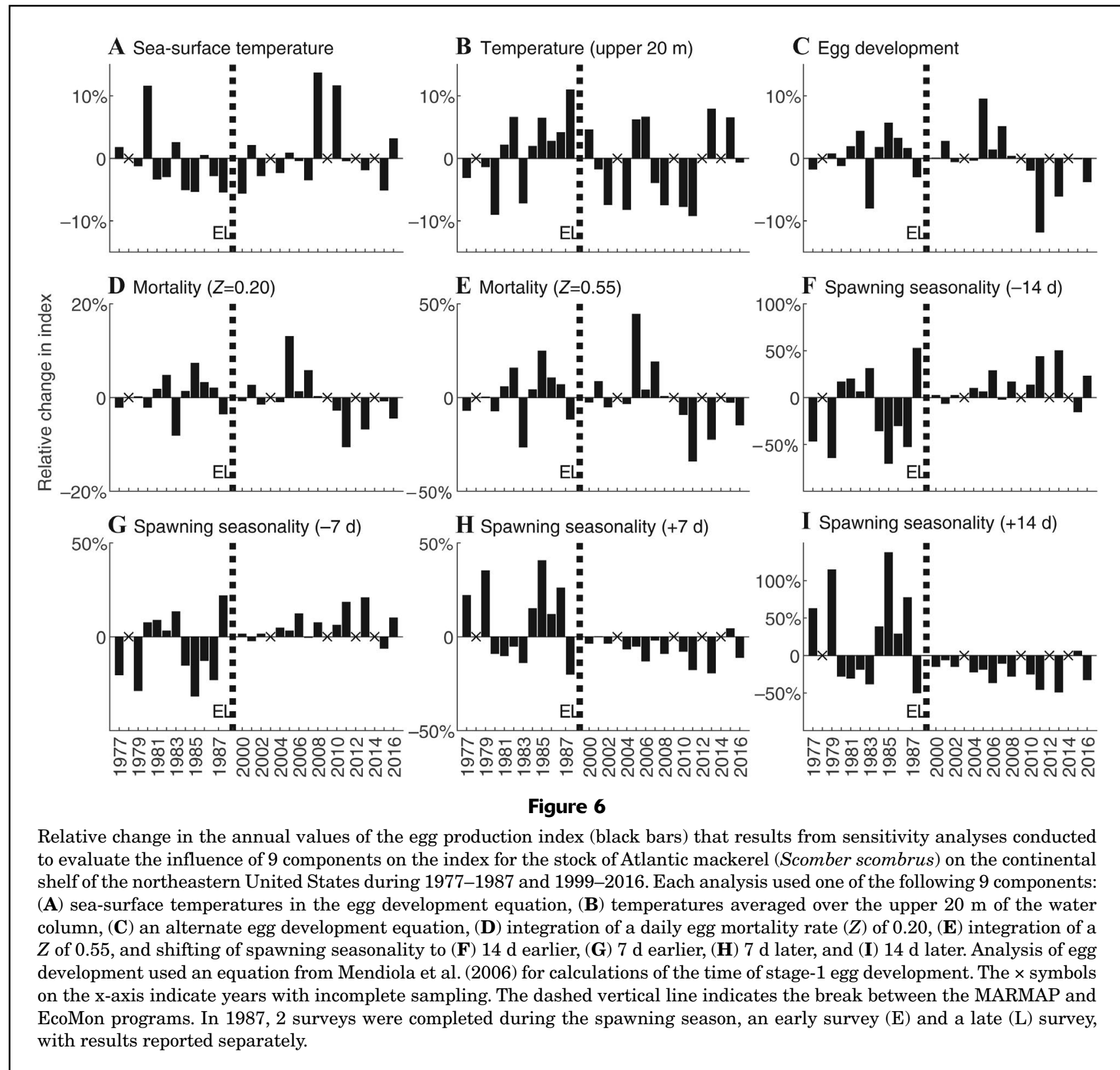

likely to have occurred than field or laboratory biases and were evaluated by using sensitivity analyses.

The 3 sensitivity analyses that focused on egg incubation times revealed that uncertainty in the duration of stage-1 eggs had a relatively minor effect on both the scale and trend of egg production estimates. Both the equation we used for temperature-dependent stage-1 egg development time (Lockwood et al. ${ }^{10}$ ) and an alternative equation used in the sensitivity analysis (Mendiola et al., 2006) were based on studies of Atlantic mackerel in the eastern Atlantic Ocean, with only minor differences resulting from switching between the 2 equations. Total time to hatching (versus stage-1 duration) in a third study from U.S. waters (Worley, 1933) differed from that in the study by Lockwood et al. ${ }^{10}$ by $5 \%$ on average across a temperature range of $10-21^{\circ} \mathrm{C}$, indicating that the use of results from studies in the eastern Atlantic Ocean was appropriate. Sampling to resolve vertical distribution of eggs of Atlantic mackerel (e.g., Sette, 1943) occurred prior to the development of opening-and-closing plankton nets (e.g., Wiebe et al., 1976). Although the limited data on the vertical distribution of eggs of Atlantic mackerel leads to some uncertainty concerning the use of the average temperature at a depth from the surface to $10 \mathrm{~m}$ in the egg development equation, this uncertainty had only a minor effect on the index. In aggregate, these results indicate that lab studies to refine estimates of development times or field studies to resolve vertical distributions of eggs are of low priority. 
The inclusion of egg mortality in the calculations led to an increase in estimates of the scale of egg production and spawning stock biomass. Effects on trends in the index were minor and driven by year-to-year differences in the temperature at which eggs were collected and, therefore, in the durations of stage- 1 development. A number of early studies estimated egg mortality at low rates, and those results, combined with the short duration of stage-1 development of eggs, indicate that excluding this poorly estimated parameter results in only a minor underestimate in the calculation of annual egg production. In contrast, a recent study estimated mortality of stage-2 eggs at $0.54 / \mathrm{d}$ in waters of the eastern Atlantic Ocean (Portilla et al., 2007); it was not possible to directly estimate stage-1 mortality with that method. If this higher mortality estimate is accurate for mortality in the western Atlantic Ocean, the actual annual egg production, and in turn spawning stock biomass values, would be $\approx 70 \%$ higher than our estimates. Additional work to resolve egg mortality is, therefore, of primary importance if the scale of the estimated spawning stock biomass was to be directly used in a stock assessment or in development of management advice, rather than relative abundance indices, as is currently the case in both the United States and Canada.

Unlike the other changes evaluated in sensitivity analyses, results from varying the spawning seasonality function indicate that, if our assumptions are not correct, a temporal bias in the index could result. During 19771987, the seasonal timing of plankton surveys varied from year to year, and changes in spawning seasonality in the sensitivity analyses had both positive and negative effects on egg production estimates. Notably, in 1987, 2 cruises were completed, 1 cruise before and 1 cruise after the peak in spawning, and analyses of the data from both cruises yielded similar estimates of annual egg production. Since 2000, the window of late May-early June has been targeted for sampling; this sampling period is 1-2 weeks past the estimated average peak day of spawning. Shifting spawning earlier, therefore, resulted in a consistent increase in the index and vice versa, although the changes in index values did not change the conclusion that a severe decline had occurred in egg production of Atlantic mackerel.

The benefits of estimating spawning seasonality directly each year is clear from this sensitivity analysis. However, unlike for sampling in the Gulf of St. Lawrence, there is not a ready way to acquire a representative sample of adult Atlantic mackerel from the U.S. fishery during spawning. Periodically shifting the timing of the plankton sampling cruise earlier or sampling plankton during multiple cruises in a spawning season could address this issue, but such efforts would face logistical constraints. Importantly, sampling on the NEFSC spring bottom-trawl survey that operates from south to north from March through late April collects very few mackerel eggs and ripe adults. The signal of a substantial shift in spawning seasonality should be picked up on this cruise, but such a shift to date has not been observed.
Additionally, direct measures of spawning seasonality in the Gulf of St. Lawrence have shown limited year-to-year variability with no evidence of a trend in the timing of spawning (Grégoire et al. ${ }^{4}$ ).

In developing the combined U.S.-Canada index for use in the stock assessment, we assumed that either only a small proportion of egg production occurs outside of the areas sampled or that this proportion does vary substantially over time. In U.S. waters, Atlantic mackerel do not occupy waters south of the southern boundary of sampling. Whether mackerel spawn in deep waters off the northeastern U.S. continental shelf is less certain, as this area has been sampled infrequently and only during certain seasons (Richardson et al., 2016). However, a 9-13 May 1993 cruise to this area did not collect larvae of Atlantic mackerel (Hare et al., 2001), and sea-surface temperatures off the shelf are generally $>13^{\circ} \mathrm{C}$ during May. In contrast, sea-surface temperatures inshore of the sampling area are appropriate for spawning of Atlantic mackerel, and mackerel eggs have been collected in Long Island Sound, although at abundances lower than those of collections in offshore regions in the same year (Peterson and Ausubel, 1984).

The area inshore of the sampling domain is $\approx 7 \%$ of the total area of the shelf; therefore, much higher inshore egg abundances would be required to have a substantial effect on the index trends. Nonetheless, efforts to evaluate inshore spawning should be pursued. Within waters of Canada, exploratory cruises to the Scotian Shelf and the southern coast of Newfoundland in 2009 collected eggs of Atlantic mackerel but at levels that indicate the magnitude of spawning outside the Gulf of St. Lawrence was low (Grégoire et al. ${ }^{11}$ ). Sampling in waters of northeastern Newfoundland in 2015 and 2016 did not find mackerel eggs. Overall, there is no evidence of sufficient levels of spawning outside the sampling area to bias the combined U.S.-Canadian egg index, although exploratory cruises to potential areas used by Atlantic mackerel for spawning should be periodically pursued to further test this assumption.

The conversion of annual egg production to spawning stock biomass by using year-specific values of fecundity based on measured gonad weights presents one final source of uncertainty. Within the sampling in Canada, fecundity per unit of biomass was lower early in the time series, when the stock was high (average in 1980-1985: $520,000 \mathrm{eggs} / \mathrm{kg}$ ), than later in the time series when the stock was low (average in 2010-2016: 890,000 eggs $/ \mathrm{kg}$ ), leading to a slightly more extreme decline in estimates of spawning stock biomass than the decline in annual egg production. In the United States, fecundity information was collected in 1977 and 1987, and these fecundity values relative to total length were very similar to those

\footnotetext{
${ }^{11}$ Grégoire, F., J.-L. Beaulieu, M.-H. Gendron, and D. LeBlanc. 2013. Results of the Atlantic mackerel (Scomber scombrus L.) egg survey conducted on the Scotian Shelf and Newfoundland's South Coast in 2009. Can. Sci. Advis. Secret. Res. Doc. 2012/127, 25 p. [Available from website.]
} 
obtained in Canada for Atlantic mackerel with $\mathrm{FL}<35 \mathrm{~cm}$ but were higher in larger fish (Morse, 1980; Griswold and Silverman, 1992). As is the case with estimating spawning seasonality annually, estimating fecundity annually in the United States would be challenging but could reduce uncertainty and remove a potential source of bias.

\section{Spatial distribution of egg production}

Within the northeastern U.S. continental shelf, there has been a general northeastward shift in Atlantic mackerel egg distribution. This northeastward shift also has been evident in the sampling of adults on the bottomtrawl survey in March and April (Overholtz et al., 2011; Radlinski et al., 2013; Walsh et al., 2015), in the distribution of commercial landings during the winter and spring fishery (NEFSC, 2018), in the distribution of recreational catch, and not surprisingly, in the spatial patterns of larval Atlantic mackerel on the plankton survey (McManus et al., 2018). We sought to examine only whether the area of sea-surface temperatures preferred by Atlantic mackerel for spawning had declined because a fuller evaluation of larval mackerel habitat, which included concurrent zooplankton collections, has been performed by using data from the MARMAP and EcoMon programs (McManus et al., 2018). A slight decline in the area of suitable spawning temperatures was evident; however, this decline was not significant. The warming of waters on the shelf off the northeastern United States alone could not fully account for the near absence of eggs in some historical spawning areas, although these temperature changes likely have contributed to some of the observed distribution shift. Results from the more complex larval distribution models similarly indicate that, although there has been some decline in habitat of Atlantic mackerel, this decline could not account for the drop in larval abundance or the restriction of the spawning area in recent years.

At a broader spatial scale, our results indicate that the majority of spawning of Atlantic mackerel occurred in the Gulf of St. Lawrence in all years analyzed since 1979 and that the relative importance of the spawning ground in the Gulf of St. Lawrence has increased over the past 4 decades. This finding of a dominant spawning ground in Canada since 1979 contrasts with the conclusions of Sette (1943) that $90 \%$ of spawning in the early 1900 s occurred in U.S. waters, based on a comparison of. egg numbers in the United States during 1927-1932 to those from a survey conducted in the Gulf of St. Lawrence in 1914-1915. In addition to the differences in the years of sampling, there were issues with the sampling done in Canada in 1914-1915 that made the results of these comparisons highly uncertain, including unrecorded tow times leading to unknown water volume sampled for some stations, haphazardly spaced stations, the reliance on only tows of neuston nets (Sette, 1943), and the absence of tows in many areas of the Gulf of St. Lawrence that have supported higher egg abundances in recent decades (Grégoire et al. ${ }^{3}$ ).
Our reanalysis of the data from the cruise undertaken in 1932 in the United States, which used a different method, produced a similar estimate of annual egg production on the northeastern U.S. shelf ( $\approx 55$ trillion eggs; $100,000 \mathrm{t}$ of spawning stock biomass) as the original Sette (1943) analysis. Interestingly, the level of U.S. egg production in 1932 was similar to estimates for 1985-1987 in U.S. waters (mean: 51 trillion eggs), and population-wide landings were also comparable (78,000 $\mathrm{t}$ in 1932; mean of 73,000 t for 1985-1987) (Hoy and Clark ${ }^{2}$; NEFSC, 2018). However, the results of surveys in 1987 indicate that $>90 \%$ of spawning occurred in the Gulf of St. Lawrence rather than the $10 \%$ that was suggested to have occurred in 1932. Comparison of survey data from these 2 time periods indicates that either fishing mortality of the entire stock was much higher in the early 1930s than in the late 1980s (i.e., similar landings but a lower total stock biomass) or that a much higher percentage of spawning occurred in Canada in the early 1930s than was originally estimated.

Given the lack of clear age truncation in the 1930s (Sette, 1950) and the caveats about the sampling in the Gulf of St. Lawrence during 1914-1915, caution should be applied in concluding that the dominant spawning site for Atlantic mackerel has switched from U.S. waters to Canada waters over the past century. On the other hand, comparative U.S.-Canada data from 1979 and 1983 do indicate that spawning in the United States was closer in scale to spawning in Canada during that time period, with the high levels of spawning occurring in the United States as early as 1977 but not in 1966. Overall, these results indicate that there has been a shift in recent decades to the northern contingent accounting for a higher proportion of spawning by the entire stock, but our findings leave unanswered the question of whether there are periods when the southern contingent is dominant.

Both environmental factors and population characteristics, such as abundance and length structure, have been observed to underlie changes in fish distribution and spawning distribution through time (MacCall, 1990; Bell et al., 2014; Secor, 2015). Both the northern and southern contingents of Atlantic mackerel in the western Atlantic Ocean have experienced a shrinkage in spawning area as the stock has declined and age structure has become truncated, changes that are consistent with MacCall's (1990) basin model of habitat selection. In the eastern Atlantic Ocean, there has been an expansion in the extent of the spawning area used by Atlantic mackerel as the stock has increased in abundance; however, even when temperature and abundance have been accounted for, it has not been possible to explain all the changes in spawning distribution (Brunel et al., 2018). Patterns on both sides of the Atlantic Ocean indicate that a complexity of factors underlie the observed changes in distribution (McManus et al., 2018).

In the western Atlantic Ocean, one factor that we have little understanding of but that likely affects broad-scale spawning distribution is how the spawning grounds in the Gulf of St. Lawrence and the United States are connected. Sette (1950) stated that interannual stability 
in the migration patterns of specific year classes indicates a strong degree of fidelity by individuals to spawning grounds but that there was a lack of evidence for or against intergenerational stability in migration. The question of whether the northern and southern contingents are different populations persists to this day because there is no evidence of genetic differentiation or natal homing. Egg abundance in waters of Canada increased for many years after the 2 dominant year classes over the past 35 years (i.e., the year classes of 1982 and 1999) reached maturity; a similar increase in egg production has not been observed for Atlantic mackerel in U.S. waters. Results from reproductive sampling also indicate that these 2 year classes made up a majority of spawners in waters of Canada and that the 1982 year class was not a dominant influence in U.S. waters (Griswold and Silverman, 1992). Some stability year-toyear is likely to be observed in the relative magnitude of spawning in the 2 spawning grounds, stability driven by the fidelity of strong year classes to different spawning grounds. Whether the current pattern of dominance by the spawning ground in Canada will persist is tied in part to the sporadic recruitment of year classes to the 2 contingents, a process that is poorly understood and likely will remain difficult to predict.

The ultimate purpose of this work was to contribute to a stock-wide index of abundance for Atlantic mackerel in the western North Atlantic Ocean that could be incorporated as a fishery-independent index into the U.S. stock assessment completed in 2017. Because of disparate data sources in the previous assessment done in 2010, the model was not accepted for providing management advice, and subsequently the status of Atlantic mackerel in the United States was officially designated as unknown. The assessment model used in 2017 included additional years of catch-at-age data indicating continued age truncation (e.g., very few age-7 and older fish have been encountered since 2012) despite low landings. The joint U.S.-Canada egg-based estimate of spawning stock biomass was also included as a relative index (NEFSC, 2018). The results from the model used in 2017, which indicate very low population levels, was consistent with a broad consensus on the status of the stock and was ultimately accepted for management advice. Going forward, it is important to continue the field sampling and laboratory work that are essential to maintaining the egg index, while developing new studies that can address some of the uncertainties in this approach.

\section{Acknowledgments}

We thank L. Girard for expert help with fish egg identification and staging. We also thank A. Smith and T. Doniol-Valcroze for providing data for Suppl. Table 1 and R. McBride for reviewing an earlier version of this manuscript. This work was funded by a NOAA Improve a Stock Assessment grant to the senior author and K. Curti for fiscal year 2015.

\section{Literature cited}

Astthorsson, O. S., H. Valdimarsson, A. Gudmundsdottir, and G. J. Óskarsson.

2012. Climate-related variations in the occurrence and distribution of mackerel (Scomber scombrus) in Icelandic waters. ICES J. Mar. Sci. 69:1289-1297. Crossref

Banzon, V., T. M. Smith, T. M. Chin, C. Liu, and W. Hankins.

2016. A long-term record of blended satellite and in situ sea-surface temperature for climate monitoring, modeling and environmental studies. Earth Syst. Sci. Data 8:165-176. Crossref

Bell, R. J., D. E. Richardson, J. A. Hare, P. D. Lynch, and P. S. Fratantoni.

2014. Disentangling the effects of climate, abundance, and size on the distribution of marine fish: an example based on four stocks from the Northeast US shelf. ICES J. Mar. Sci. 72:1311-1322. Crossref

Berge, J., K. Heggland, O. J. Lønne, F. Cottier, H. Hop, G. W. Gabrielsen, L. Nøttestad, and O. A. Misund.

2015. First records of Atlantic mackerel (Scomber scombrus) from the Svalbard Archipelago, Norway, with possible explanations for the extensions of its distribution. Arctic 68:54-61. Crossref

Bernal, M., Y. Stratoudakis, S. Coombs, M. M. Angelico, A. Lago de Lanzós, C. Porteiro, Y. Sagarminaga, M. Santos, A. Uriarte, E. Cunha, et al.

2007. Sardine spawning off the European Atlantic coast: characterization of and spatio-temporal variability in spawning habitat. Prog. Oceanogr. 74:210-227. Crossref

Bernal, M., S. Somarakis, P. R. Witthames, C. J. G. van Damme, A. Uriarte, N. C. H. Lo, and M. Dickey-Collas

2012. Egg production methods in marine fisheries: an introduction. Fish. Res. 117-118:1-5. Crossref

Berrien, P. L.

1975. A description of Atlantic mackerel, Scomber scombrus, eggs and early larvae. Fish. Bull. 73:186-192.

1978. Eggs and larvae of Scomber scombrus and Scomber japonicus in continental shelf waters between Massachusetts and Florida. Fish. Bull. 76:95-115.

Berrien, P. L., N. A. Naplin, and M. R. Pennington.

1981. Atlantic mackerel, Scomber scombrus, egg production and spawning population estimates for 1977 in the Gulf of Maine, Georges Bank, and Middle Atlantic Bight. Rapp. P.-v. Run. Cons. Int. Explor. Mer 178:279-288.

Berrien, P., W. Morse, and M. Pennington.

1984. Recent estimates of adult spawning stock biomass off the northeastern United States from MARMAP ichthyoplankton surveys. NOAA Tech. Memo. NMFS-F/NEC-30, $111 \mathrm{p}$.

Brunel, T., C. J. G. van Damme, M. Samson, and M. Dickey-Collas.

2018. Quantifying the influence of geography and environment on the northeast Atlantic mackerel spawning distribution. Fish. Oceanogr. 27:159-173. Crossref

Coombs, S. H., D. Morgans, and N. C. Halliday.

2001 . Seasonal and ontogenetic changes in the vertical distribution of eggs and larvae of mackerel (Scomber scombrus L.) and horse mackerel (Trachurus trachurus L.). Fish. Res. 50:27-40. Crossref

de Lafontaine, Y., and D. Gascon.

1989. Ontogenetic variation in the vertical distribution of eggs and larvae of Atlantic mackerel (Scomber scombrus). Rapp. P.-v. Reun. Cons. Int. Explor. Mer 191:137-145.

Deroba, J. J., G. Shepherd, F.Gregiore, J. Nieland, and J. S. Link.

2010. Stock assessment of Atlantic mackerel in the Northwest Atlantic-2009. Transboundary Resour. Assess. Comm. Ref. Doc. 2010/01, 59 p. [Available from website.] 
DFO (Fisheries and Oceans Canada).

2017. Assessment of the Atlantic mackerel stock for the Northwest Atlantic (subareas 3 and 4) in 2016. Can. Sci. Advis. Secr. Sci. Advis. Rep. 2017/034, 15 p. [Available from website.]

Dransfeld, L., O. Dwane, J. Molloy, S. Gallagher, and D. G. Reid.

2005. Estimation of mackerel (Scomber scombrus L., 1758) and horse mackerel (Trachurus trachurus L., 1758) daily egg production outside the standard ICES survey area. ICES J. Mar. Sci. 62:1705-1710. Crossref

Griswold, C. A., and M. J. Silverman.

1992. Fecundity of the Atlantic mackerel (Scomber scombrus) in the northwest Atlantic in 1987. J. Northwest Atl. Fish. Sci. 12:35-40. Crossref

Hare, J. A., M. P. Fahay, and R. K. Cowen.

2001. Springtime ichthyoplankton of the slope region off the north-eastern United States of America: larval assemblages, relation to hydrography and implications for larval transport. Fish. Oceanogr. 10:164-192. Crossref

Hughes, K. M., L. Dransfeld, and M. P. Johnson.

2014. Changes in the spatial distribution of spawning activity by north-east Atlantic mackerel in warming seas: 19772010. Mar. Biol. 161:2563-2576. Crossref

Jansen, T., S. Post, T. Kristiansen, G. J. Óskarsson, J. Boje,

B. R. MacKenzie, M. Broberg, and H. Siegstad.

2016. Ocean warming expands habitat of a rich natural resource and benefits a national economy. Ecol. Appl. 26:2021-2032. Crossref

Kendall, A. W., and D. Gordon.

1981. Growth rate of Atlantic mackerel (Scomber scombrus) larvae in the Middle Atlantic Bight. Rapp. P.-V. Reun. Cons. Int. Explor. Mer. 178:337-341.

Lasker, R. (ed).

1985. An egg production method for estimating spawning biomass of pelagic fish: application to northern anchovy, Engraulis mordax. NOAA Tech. Rep. NMFS 36, 99 p.

Lewis, L. A., D. E. Richardson, E. V. Zakharov, and R. Hanner. 2016. Integrating DNA barcoding of fish eggs into ichthyoplankton monitoring programs. Fish. Bull. 114:153-165. Crossref

MacCall, A. D.

1990. Dynamic geography of marine fish populations, $153 \mathrm{p}$. Washington Univ. Press, Seattle, WA.

MacKenzie, B. R., M. R. Payne, J. Boje, J. L. Høyer, and H. Siegstad. 2014. A cascade of warming impacts brings bluefin tuna to Greenland waters. Global Change Biol. 20:2484-2491. Crossref

McManus, M. C., J. A. Hare, D. E. Richardson, and J. S. Collie.

2018. Tracking shifts in Atlantic mackerel (Scomber scombrus) larval habitat suitability on the Northeast U.S. continental shelf. Fish. Oceanogr. 27:49-62. Crossref

Mendiola, D., P. Alvarez, U. Cotano, E. Etxebeste, and A. M. de Murguia.

2006. Effects of temperature on development and mortality of Atlantic mackerel fish eggs. Fish. Res. 80:158-168. Crossref

Morse, W. W.

1980. Spawning and fecundity of Atlantic mackerel, Scomber scombrus, in the Middle Atlantic Bight. Fish. Bull. 78:103-108.

NEFSC.

2006. 42nd Northeast regional stock assessment workshop (42th SAW) stock assessment report. Part A: silver hake, Atlantic mackerel, and northern shortfin squid. Natl. Mar. Fish. Serv., Northeast Fish. Sci. Cent. Ref. Doc. 06-09a, 284 p. [Available from website.]
2018. 64th Northeast regional stock assessment workshop (64th SAW) assessment summary report. Natl. Mar. Fish. Serv., Northeast Fish. Sci. Cent. Ref. Doc. 18-03, 27 p. [Available from website.]

Nøttestad, L., K. R. Utne, G. J. Óskarsson, S. P. Jónsson, J. A. Jacobsen, Ø. Tangen, V. Anthonypillai, S. Aanes, J. H. Vølstad, M. Bernasconi, et al.

2016. Quantifying changes in abundance, biomass, and spatial distribution of Northeast Atlantic mackerel (Scomber scombrus) in the Nordic seas from 2007 to 2014. ICES J. Mar. Sci. 73:359-373. Crossref

Óskarsson, G. J., A. Gudmundsdottir, S. Sveinbjörnsson, and P. Sigurðsson.

2016. Feeding ecology of mackerel and dietary overlap with herring in Icelandic waters. Mar. Biol. Res. 12:16-29. Crossref

Overholtz, W. J., J. A. Hare, and C. M. Keith.

2011. Impacts of interannual environmental forcing and climate change on the distribution of Atlantic mackerel on the U.S. Northeast continental shelf. Mar. Coast. Fish. 3:219-232. Crossref

Pelletier, L.

1986. Fécondité du maquereau bleu, Scomber scombrus L., du golfe du Saint Lauerent. Can. Tech. Rep. Fish. Aquat. Sci. 1467, 37 p. [Available from website.]

Peterson, W. T., and S. J. Ausubel.

1984. Diets and selective feeding by larvae of Atlantic mackerel, Scomber scombrus, on zooplankton. Mar. Ecol. Prog. Ser. 17:65-75.

Portilla, E., E. McKenzie, D. Beare, and D. Reid.

2007. Estimating natural interstage egg mortality of Atlantic mackerel (Scomber scombrus) and horse mackerel (Trachurus trachurus) in the Northeast Atlantic using a stochastic model. Can. J. Fish. Aquat. Sci. 64:1656-1668. Crossref

Radlinski, M. K., M. A. Sundermeyer, J. J. Bisagni, and S. X. Cadrin.

2013. Spatial and temporal distribution of Atlantic mackerel (Scomber scombrus) along the northeast coast of the United States, 1985-1999. ICES J. Mar. Sci. 70:1151-1161. Crossref

Richardson, D. E., J. A. Hare, W. J. Overholtz, and D. L. Johnson. 2010. Development of long-term larval indices for Atlantic herring (Clupea harengus) on the northeast US continental shelf. ICES J. Mar. Sci. 67:617-627. Crossref

Richardson, D. E., K. E. Marancik, J. R. Guyon, M. E. Lutcavage, B. Galuardi, C. H. Lam, H. J. Walsh, S. Wildes, D. A. Yates, and

J. A. Hare.

2016. Discovery of a spawning ground reveals diverse migration strategies in Atlantic bluefin tuna (Thunnus thynnus). Proc. Natl. Acad. Sci. U.S.A. 113:3299-3304. Crossref

Secor, D. H.

2015. Migration ecology of marine fishes, 304 p. John Hopkins Univ. Press, Baltimore, MD.

Sette, O. E.

1943. Biology of Atlantic mackerel (Scomber scombrus) of North America. Part 1: early life history including growth, drift, and mortality of the egg and larval populations. Fish. Bull. 50:149-237.

1950. Biology of the Atlantic mackerel (Scomber scombrus) of North America. Part 2: migrations and habits. Fish. Bull. 51:251-358.

Shearman, R. K., and S. J. Lentz.

2010. Long-term sea surface temperature variability along the U.S. East Coast. J. Phys. Oceanogr. 40:1004-1017. Crossref 
Spijkers, J., and W. J. Boonstra.

2017. Environmental change and social conflict: the northeast Atlantic mackerel dispute. Reg. Environ. Chang. 17:1835-1851. Crossref

Stratoudakis, Y., M. Bernal, K. Ganias, and A. Uriarte.

2006. The daily egg production method: recent advances, current applications and future challenges. Fish Fish. 7:35-57. Crossref

Thompson, A. B.

1989. Mackerel (Scomber scombrus) egg mortality: the western mackerel stock in Biscay and the western approaches in 1977, 1980, 1983 and 1986. J. Plankton Res. 11:12971306. Crossref

van der Lingen, C. D., L. Hutchings, D. Merkle, J. J. van der Westhuizen, and J. Nelson.

2001. Comparative spawning habitats of anchovy (Engraulis capensis) and sardine (Sardinops sagax) in the Southern Benguela upwelling ecosystem. In Spatial processes and management of marine populations. Univ. Alaska Sea
Grant Coll. Program Rep. AK-SG-01-02 (G. H. Kruse, N. Bez, A. Booth, M. W. Dorn, S. Hills, R. N. Licius, D. Pelletier, C. Roy, S. J. Smith, and D. Witherell, eds.), p. 185-209. Univ. Alaska Sea Grant, Fairbanks, AK. [Available from website.]

Walsh, H. J., D. E. Richardson, K. E. Marancik, and J. A. Hare.

2015. Long-term changes in the distributions of larval and adult fish in the Northeast U.S. Shelf Ecosystem. PLoS ONE 10(9):e0137382. Crossref

Ware, D. M., and T. C. Lambert.

1985. Early life history of Atlantic mackerel (Scomber scombrus) in the southern Gulf of St. Lawrence. Can. J. Fish. Aquat. Sci. 42:577-592. Crossref

Wiebe, P. H., K. H. Burt, S. H. Boyd, and A. W. Morton.

1976. A multiple opening/closing net and environmental sensing system for sampling zooplankton. J. Mar. Res. 34:313-326.

Worley, L. G.

1933. Development of the egg of the mackerel at different constant temperatures. J. Gen. Physiol. 16:841-857. Crossref 